\title{
Inhalation of hypertonic saline aerosol enhances mucociliary clearance in asthmatic and healthy subjects
}

\author{
E. Daviskas*, S.D. Anderson*, I. Gonda**, S. Eberl+, S. Meikle+, \\ J.P. Seale ${ }^{++}$, G. Bautovich ${ }^{+}$
}

Inhalation of hypertonic saline aerosol enhances mucociliary clearance in asthmatic and healthy subjects. E. Daviskas, S.D. Anderson, I. Gonda, S. Eberl, S. Meikle, J.P. Seale, G. Bautovich. CERS Journals Ltd 1996.

ABSTRACT: Hyperosmolarity of the airway surface liquid (ASL) has been proposed as the stimulus for hyperpnoea-induced asthma. We found previously that mucociliary clearance (MCC) was increased after isocapnic hyperventilation (ISH) with dry air, and we proposed that the increase related to transient hyperosmolarity of the ASL. We investigated the effect of increasing the osmolarity of the ASL on MCC, by administering an aerosol of concentrated salt solution.

MCC was measured using ${ }^{99 \mathrm{~m} T c}$-sulphur colloid, gamma camera and computer analysis in $\mathbf{1 2}$ asthmatic and $\mathbf{1 0}$ healthy subjects on three separate days, involving administration of each of the following: 1) ultrasonically nebulized $14.4 \%$ saline; 2) ultrasonically nebulized $0.9 \%$ saline; and 3 ) no aerosol intervention (control).

The (mean \pm SD) volume of nebulized $14.4 \%$ saline was $2.2 \pm 1.2 \mathrm{~mL}$ for asthmatics and $3.2 \pm 0.7 \mathrm{~mL}$ for healthy subjects. This volume was delivered over a period of $5.4 \pm 1.3$ and $6.4 \pm 0.7 \mathrm{~min}$ for asthmatic and healthy subjects, respectively. The airway response to $14.4 \%$ saline was assessed on a separate visit and the fall in forced expiratory volume in one second (FEV1) was $22 \pm 4 \%$ in the asthmatic and $3 \pm 2 \%$ in the healthy subjects. Compared to the MCC with the $0.9 \%$ saline and control, the hypertonic aerosol increased MCC in both groups. In asthmatic subjects, MCC of the whole right lung in $1 \mathrm{~h}$ was $68 \pm 10 \%$ with $14.4 \%$ saline $v s 44 \pm 14 \%$ with $0.9 \%$ saline and 39 $\pm 13 \%$ with control. In healthy subjects, MCC of the whole right lung in $1 \mathrm{~h}$ was $53 \pm 12 \%$ with $14.4 \%$ saline vs $41 \pm 15 \%$ with $0.9 \%$ saline and $36 \pm 13 \%$ with control.

We conclude that an increase in osmolarity of the airway surface liquid increases mucociliary clearance both in asthmatic and healthy subjects. These findings are in keeping with our previous suggestion that the increase in mucociliary clearance after isotonic hyperventilation with dry air is due to a transient hyperosmolarity of the airway surface liquid.

Eur Respir J., 1996, 9, 725-732.
Depts of * Respiratory and +Nuclear Medicine, Royal Prince Alfred Hospital, Sydney, Australia. **Aradigm Corporation, Hayward, CA, USA. ++Dept of Pharmacology, University of Sydney, Sydney, Australia.

Correspondence: S.D. Anderson

Dept of Respiratory Medicine

PCP 9, Royal Prince Alfred Hospital

Missenden Rd

Camperdown

Sydney NSW 2050

Australia

\section{Keywords: Asthma}

hyperosmolarity

mucociliary clearance

Received: July 181995

Accepted after revision January 91996

This study was supported by a grant from the National Health \& Medical Research Council of Australia.
We have previously found that mucociliary clearance (MCC) increases immediately after hyperventilation with dry air both in asthmatic and healthy subjects [1] at the time that asthmatic subjects develop airway narrowing. Although the mechanism for this increase is unknown, we postulated that the increase in MCC after hyperventilation with dry air is due to a transient hyperosmolarity of the airway surface liquid [1]. It is possible that the increase in MCC and the bronchoconstriction that follows hyperventilation with dry air share a common mechanism.

Inhalation of hypertonic saline aerosol $(7 \%)$ has been shown to increase mucociliary clearance in patients with bronchitis [2] and cystic fibrosis [3] who have impaired baseline mucociliary clearance. Although, these studies suggest that hypertonic saline stimulates the mucociliary system, there are no reported studies of the effect of hypertonic saline on the MCC in asthmatic and healthy subjects with normal baseline mucociliary clearance.
The aim of the present study was to investigate the effect of a hyperosmolar stimulus on MCC in asthmatic and healthy subjects. The strength of the hyperosmolar stimulus was chosen such that the effects of depositing a high volume of fluid in the upper and central airways could be avoided. Inhalation of hypertonic saline provokes airway narrowing in asthmatic subjects [4]. Therefore, for the present experiments, for convenience of the subjects and for reasons of safety, the volume of saline delivered was such that it induced only a mild bronchoconstriction in the asthmatic subjects.

\section{Material and methods}

The study was approved by the Ethics Review Committee of Central Sydney Area Health Service and informed consent was obtained in writing from all subjects before they participated in the study. 


\section{Subjects}

Twelve asthmatic and 10 healthy volunteers took part in the study. Their anthropometric data are presented in table 1. The asthmatic subjects had stable asthma and a resting forced expiratory volume in one second (FEV1) $>85 \%$ of predicted, except for one subject (No. 7) (table $1)$. Most of the asthmatics were receiving $\beta$-agonists as needed with or without inhaled corticosteroids (either beclomethasone or budesonide). None of the asthmatic subjects was taking theophylline. All asthmatics withheld their medication for at least $8 \mathrm{~h}$ before beginning the protocol each day. All subjects were asked not to take any nonsteroidal anti-inflammatory drugs or antihistamines for at least $48 \mathrm{~h}$ prior to each study day. None of the subjects had a history of cigarette smoking and none had a lower respiratory tract infection in the 6 weeks prior to each study.

\section{Study design}

The study involved four visits, which were at least $48 \mathrm{~h}$ apart. The procedure on each visit was as follows. Visit 1: spirometry before and after hypertonic saline.
Visits 2-4: 1) spirometry; 2) radioaerosol inhalation; 3) emission anterior/posterior images (static), 7 min after the mid-inhalation time of the radioaerosol; 4) intervention (up to $7.5 \mathrm{~min}$ ); and 5) serial emission anterior/posterior images (dynamic) for $45 \mathrm{~min}$. On Visit 2, a transmission image was taken before the radioaerosol inhalation.

\section{Interventions}

Different interventions were used at each visit and the order of the interventions was randomized between subjects: 1) ultrasonically nebulized $14.4 \%$ saline; 2) ultrasonically nebulized $0.9 \%$ saline; and 3 ) no aerosol intervention (control). On the control study day, nasal resting breathing occurred instead of an intervention. The method of delivering the 14.4 and $0.9 \%$ saline was identical.

\section{Measurement of lung function}

Spirometry, using a hot wire anemometer (Minato, AS500, Osaka, Japan), was measured before and after inhalation of hypertonic saline, on the first visit. All subjects

Table 1. - Anthropometric data, baseline FEV 1 , maximum fall of $F E V_{1}$ in response to inhaled $14.4 \%$ saline aerosol in the specified time, for asthmatic and healthy subjects

\begin{tabular}{|c|c|c|c|c|c|c|c|c|c|c|c|}
\hline $\begin{array}{l}\text { Sub. } \\
\text { No. }\end{array}$ & Sex & $\begin{array}{l}\text { Age } \\
\text { yrs }\end{array}$ & $\begin{array}{l}\text { Height } \\
\mathrm{cm}\end{array}$ & $\begin{array}{l}\text { FEV1 } \\
\% \text { pred }\end{array}$ & $\begin{array}{c}\mathrm{FEV} 1 / \mathrm{FVC} \\
\%\end{array}$ & $\underset{\Delta \mathrm{FEV}_{1} \%}{\operatorname{Max}}$ & $\begin{array}{c}\mathrm{PD} 15 \\
\mathrm{~mL}\end{array}$ & $\begin{array}{l}\text { Nebulized } \\
\text { volume } \\
\text { mL }\end{array}$ & $\begin{array}{l}\text { Delivery } \\
\text { time } \\
\text { min }\end{array}$ & $\begin{array}{l}\text { Total } \\
\text { Salt } \\
\text { mg }\end{array}$ & Medication \\
\hline \multicolumn{12}{|c|}{ Asthmatic subjects } \\
\hline 1 & $\mathrm{~F}$ & 20 & 166 & 100 & 91 & 19 & 0.69 & 0.8 & 5.5 & 115 & $\mathrm{~S}$ \\
\hline 2 & M & 23 & 182 & 91 & 79 & 24 & 3.19 & 3.9 & 7.0 & 562 & S, B \\
\hline 3 & M & 18 & 188 & 100 & 79 & 18 & 3.4 & 4.0 & 7.5 & 576 & $\mathrm{~S}$ \\
\hline 4 & M & 22 & 175 & 106 & 90 & 23 & 0.98 & 1.4 & 3.5 & 202 & S, B \\
\hline 5 & $\mathrm{~F}$ & 21 & 162 & 115 & 82 & 21 & 1.02 & 1.5 & 4.5 & 216 & $\mathrm{~B}, \mathrm{~S}$ \\
\hline 6 & M & 19 & 179 & 97 & 80 & 25 & 0.79 & 1.2 & 5.5 & 173 & $\mathrm{~S}$ \\
\hline 7 & M & 21 & 171 & 82 & 77 & 29 & 0.44 & 0.7 & 3.5 & 101 & $\mathrm{~S}$ \\
\hline 8 & M & 36 & 180 & 106 & 73 & 16 & 2.93 & 3.8 & 6.0 & 547 & - \\
\hline 9 & $\mathrm{~F}$ & 18 & 170 & 109 & 80 & 15 & 2.33 & 2.8 & 6.0 & 403 & S, B \\
\hline 10 & M & 18 & 186 & 101 & 81 & 25 & 1.19 & 1.7 & 5.5 & 245 & S \\
\hline 11 & $\mathrm{~F}$ & 19 & 166 & 100 & 88 & 24 & 0.47 & 1.3 & 4.0 & 187 & S, BUD \\
\hline 12 & M & 21 & 184 & 86 & 82 & 23 & 0.54 & 2.7 & 6.0 & 389 & - \\
\hline Mean & & 21 & 176 & 99 & 82 & 22 & 1.5 & 2.2 & 5.4 & 310 & \\
\hline$\pm \mathrm{SD}$ & & \pm 5 & \pm 9 & \pm 9 & \pm 5 & 4 & 1.1 & 1.2 & 1.3 & 177 & \\
\hline \multicolumn{12}{|c|}{ Healthy subjects } \\
\hline 13 & $\mathrm{M}$ & 21 & 178 & 123 & 90 & 4 & NA & 3.2 & 6.0 & 461 & NA \\
\hline 14 & $\mathrm{~F}$ & 20 & 161 & 111 & 84 & 3 & NA & 2.9 & 6.0 & 418 & NA \\
\hline 15 & F & 24 & 167 & 108 & 82 & 4 & NA & 2.3 & 7.5 & 331 & NA \\
\hline 16 & $\mathrm{~F}$ & 19 & 163 & 106 & 91 & 1 & NA & 2.4 & 7.5 & 346 & NA \\
\hline 17 & M & 18 & 175 & 104 & 87 & 1 & NA & 3.0 & 7.5 & 432 & NA \\
\hline 18 & M & 20 & 182 & 95 & 82 & 4 & NA & 3.2 & 6.0 & 461 & NA \\
\hline 19 & $\mathrm{~F}$ & 21 & 165 & 108 & 88 & 7 & NA & 2.9 & 6.0 & 418 & NA \\
\hline 20 & $\mathrm{~F}$ & 21 & 171 & 129 & 92 & 1 & NA & 4.1 & 6.0 & 590 & NA \\
\hline 21 & M & 24 & 163 & 89 & 74 & 3 & NA & 4.8 & 6.0 & 346 & NA \\
\hline 22 & $\mathrm{~F}$ & 21 & 162 & 98 & 90 & 4 & NA & 3.0 & 6.0 & 432 & NA \\
\hline Mean & & 21 & 169 & 107 & 86 & 3 & & 3.2 & 6.5 & 423 & - \\
\hline$\pm \mathrm{SD}$ & & \pm 2 & \pm 7 & \pm 12 & \pm 6 & \pm 2 & & \pm 0.8 & \pm 0.7 & \pm 76 & \\
\hline
\end{tabular}

Sub: subject; M: male; F: female; S: salbutamol; B: beclomethasone dipropionate; BUD: budesonide; FEV1: forced expiratory volume in one second; $\triangle F_{E V}$ : fall in FEV1 from baseline; FVC: forced vital capacity; PD15: dose of saline that provoked a $15 \%$ fall in FEV1; NA: not applicable. 
had reproducible spirometry, which was within the normal range at rest. Predicted values for lung volumes were taken from Goldman and BeCKLAKe [5] for adults. Predicted FEV1 was calculated as $79 \%$ of the predicted vital capacity.

\section{$14.4 \%$ saline aerosol challenge}

Our aim was to study the effect of hyperosmolarity on MCC by delivering a volume of hypertonic saline that could increase the osmolarity of the airway fluid to levels that bring on mild bronchoconstriction to asthmatic subjects. While inhalation of $4.5 \%$ saline could increase the osmolarity of the airway fluid and is suitable for provoking an attack of asthma, up to $15-20 \mathrm{~mL}$ of $4.5 \%$, containing $675-900 \mathrm{mg}$ of salt, nebulized over a period of $10-15 \mathrm{~min}$, may be needed to induce a $15-20 \%$ fall in FEV1 in subjects with mild asthma [4]. The exact volume of saline aerosol that deposits in the airways is not known but it has been estimated that only $41 \%$ (range $22-58 \%$ ) of the nebulized volume is inhaled [6], and of this inhaled volume $15-35 \%$ will deposit on the first 10 generations [7]. Therefore, if $6-8 \mathrm{~mL}$ is inhaled and only $20 \%$ of this volume is deposited, this could double the volume of the first 10 generations, which has been calculated to be less than $1 \mathrm{~mL}$ [8]. Therefore, the time involved and the large volume of fluid that deposits on the airways make the $4.5 \%$ saline challenge inappropriate for studies of MCC. A concentration of $14.4 \%$ salt solution was chosen as the appropriate concentration that could alter the osmolarity of the airway fluid following deposition of only a small volume. A concentration of $14.4 \%$ saline was used by RoDwell et al. [9] with a high output nebulizer, therefore its safety and subject acceptability had been tested.

The method for delivering the $14.4 \%$ saline was similar to the method described by SMITH and ANDERSON [4]. The $14.4 \%$ saline aerosol was generated by a De Vilbiss 99 ultrasonic nebulizer (De Vilbiss, Somerset, PA, USA). The nebulizer was carefully set to deliver $0.1-$ $0.6 \mathrm{~mL} \cdot \mathrm{min}^{-1}$ of aerosol, depending on the sensitivity of the asthmatic subject. Such an output can deliver 14.4$72 \mathrm{mg} \mathrm{NaCl} \cdot \mathrm{min}^{-1}$. It was intended that the maximum nebulized volume of aerosol would be approximately 3 $\mathrm{mL}$ containing $432 \mathrm{mg} \mathrm{NaCl}$. Of this volume, if $41 \%$ is inhaled and $20 \%$ is deposited, approximately $0.25 \mathrm{~mL}$ containing $36 \mathrm{mg} \mathrm{NaCl}$ will deposit in the first 10 generations.

Subjects inhaled the aerosol at resting ventilation through a two-way valve (No. 2700; Hans Rudolph, Kansas City, MO, USA) connected to the nebulizer by Bennett tubing (Bennett Respiration Products, Los Angeles, CA, USA) $45 \mathrm{~cm}$ in length and $2 \mathrm{~cm}$ internal diameter. The unit was weighed with the tubing, but not the valve, before the challenge and after the final dose, so the total nebulized volume and the output of the nebulizer was calculated for each subject.

On Visit 1 , baseline spirometry was measured initially and $10 \mathrm{~min}$ after arrival in the laboratory. Subjects then inhaled the aerosol for $30 \mathrm{~s}, 1,2$ or 4 min depending on the airway response. Spirometry was measured in duplicate at 1 min after each time interval of challenge. The maximal response usually occurs within a minute after each challenge. The challenge stopped if there was a $20 \%$ fall in FEV1. Subjects who had a fall in FEV1 of $15 \%$ or more were selected for the study. All asthmatic subjects taking part in the MCC study had mild asthma and recovered spontaneously after the hyperosmolar saline challenge. The same protocol was followed for measuring the airway responses in healthy subjects, with maximum inhalation of approximately $3 \mathrm{~mL}$ of $14.4 \%$ saline.

On the MCC study day, the delivery of the hyperosmolar aerosol was uninterrupted. The nebulized volume and the delivery time were kept the same for each subject as on the assessment day (Visit 1). The volume and the delivery time of the $0.9 \%$ saline was the same as the hyperosmolar saline.

\section{Measurement of mucociliary clearance}

Inhalation of radioaerosol. Mucociliary clearance was assessed using a radioaerosol technique. ${ }^{99 m T c-s u l p h u r ~}$ colloid (Australian Radioisotopes, Sydney, Australia), approximately $1 \mathrm{GBq}$, was diluted in $5 \mathrm{~mL}$ of isotonic saline. The sulphur colloid particles are suitable for assessing mucociliary clearance as they are not transported across the epithelia due to their size, insolubility and stability in the airway fluid. The clearance of insoluble particles is of two kinds: 1) fast, exclusively via the mucociliary escalator; and 2) extremely slow, via macrophages. The technetium is unleachably bound to sulphur colloid and quality control procedures confirm this before use.

The radioaerosol was generated by an Inspiron Minineb jet nebulizer (C. R. Bard International Ltd) using oxygen from a cylinder set to $6 \mathrm{~L} \cdot \mathrm{min}^{-1}$. The droplets had a mass median aerodynamic diameter (MMAD) of $5.5 \mu \mathrm{m}$ and a span of 1.8 , measured by a laser diffraction technique (Malvern Mastersizer, Malvern Instruments Ltd, Spring Lane South, Malvern, Worcestershire, UK). The dilution air supplementing the flow to the mouthpiece was humidified to maintain the characteristics of the droplets [10]. The radioaerosol was delivered with a controlled breathing pattern in order to maximize deposition in the conducting airways. A closed breathing circuit was linked to a computer that allowed monitoring and control of the breathing pattern, using a target volume and target inspiratory and expiratory times [11]. The target volume, set to $450 \mathrm{~mL}$, was displayed on the screen together with the target line oscillating at set rates, aiming at a peak inspiratory flow rate of $60 \mathrm{~L} \cdot \mathrm{min}^{-1}$. The inspiratory time was set higher than the expiratory time and the subject tried to breath according to the set tidal volume and flow rates. The patient inhaled the radioaerosol for approximately $3 \mathrm{~min}$. This delivery time was chosen so that the lung counts were about 2000 count $\cdot \mathrm{s}^{-1}$ over the posterior thorax. Upon termination of the delivery of radioaerosol, the subjects removed the radioactivity from their oropharynx and the oesophagus by rinsing and gargling with water and expectorating, and by swallowing some bread and water.

Imaging. Lung images were obtained using a gamma camera (Philips Diagnost Tomo; Hamburg, Germany) fitted with a low energy, all purpose, collimator and linked to an on-line computer (DEC PDP11, Maynard, MA, USA). The images were collected in a $64 \times 64$ matrix. 
The lung fields of the subjects were delineated with anterior and posterior transmission images [12] taken with a flood source containing approximately $1.5 \mathrm{GBq}$ of ${ }^{153} \mathrm{Gd}$ in water. One minute anterior and posterior emission images (static) were collected for each subject approximately $7 \mathrm{~min}$ after the inhalation of the radioaerosol. The purpose of this image was to define the initial distribution of the radioaerosol deposition. Within 3 min post-intervention, the subject was placed in the supine position and successive $20 \mathrm{~s}$ anterior and posterior emission images (dynamic) were collected for 45 min [13]. In order to align the lung fields between the transmission, static and the dynamic images, images of markers placed on premarked positions on the subject's body were also collected at the end of each study. Care was taken that all emission images were taken at the same time after the mid-inhalation time of the radioaerosol for the three study days.

Image and data analysis. All the images were decay corrected to the mid-inhalation time. A geometric mean image (GM) was obtained from the anterior and posterior images for the transmission, static and dynamic emission images [13]. The left lung was not analysed due to possible interference from the activity in the stomach. The right lung was divided into three regions of interest: central, intermediate and peripheral [14], in order to estimate the initial deposition of the radioaerosol and for regional analysis of the data. An estimate of the initial deposition was obtained from the activity of the static emission GM image by calculating the penetration index (PI) as follows:

$$
\mathrm{PI}=\frac{\text { counts } \cdot \mathrm{min}^{-1} \text { in peripheral region }}{\text { counts } \cdot \mathrm{min}^{-1} \text { in central region }}
$$

A bi-exponential function was fitted to the curve obtained from the dynamic GM images, using a nonlinear least squares method (PCNONLIN, SCI, Software, Lexington, KY, USA). The total counts of the whole right lung and defined regions in the static emission GM image, measured before the intervention, was taken as the initial counts and expressed as $100 \%$ retention. The counts of the whole right lung and defined regions in the dynamic emission GM images, measured after the intervention, were expressed as a percentage of the initial counts. Mucociliary clearance $(\%)$ was the difference between the initial counts and the percentage retained at the specified time. Data from the best fit were used to calculate the percentage clearance during and post intervention as follows:

$\begin{aligned} & \text { initial counts - counts at } 1 \mathrm{~min} \\ & \text { post-intervention } \\ & \text { during intervention }\end{aligned}$
$\begin{aligned} & \text { clearance } \\ & \text { post intervention }\end{aligned}=$
$\begin{aligned} & \text { Total } \% \text { clearance in } 1 \mathrm{~h}- \\ & \text { clearance during intervention }\end{aligned}$

The $\%$ clearance $\cdot \mathrm{min}^{-1}$ for each $10 \mathrm{~min}$ interval postintervention was also calculated.

\section{Statistical analysis}

Analysis of variance with repeated measures (twofactor ANOVA) was performed to compare the effect of hypertonic saline on clearance during and post-inhalation of saline between the two groups. Duncan's multiple range test was used to compare the clearance with the three interventions. The same analysis was also done for the clearance rate for each 10 min interval post-intervention. If the response of the interventions was different in the two groups then one-factor ANOVA was performed for each group separately.

Comparison of the deposition of radioaerosol on the three study days of both groups was performed using analysis of variance with repeated measures (two-factor ANOVA).

\section{Results}

Inhalation of $14.4 \%$ saline aerosol, compared to $0.9 \%$ saline and the control (no aerosol intervention) increased mucociliary clearance both in the asthmatic and the healthy subjects (fig. 1a and b). MCC was increased in the whole

a) Asthmatic Subject 10

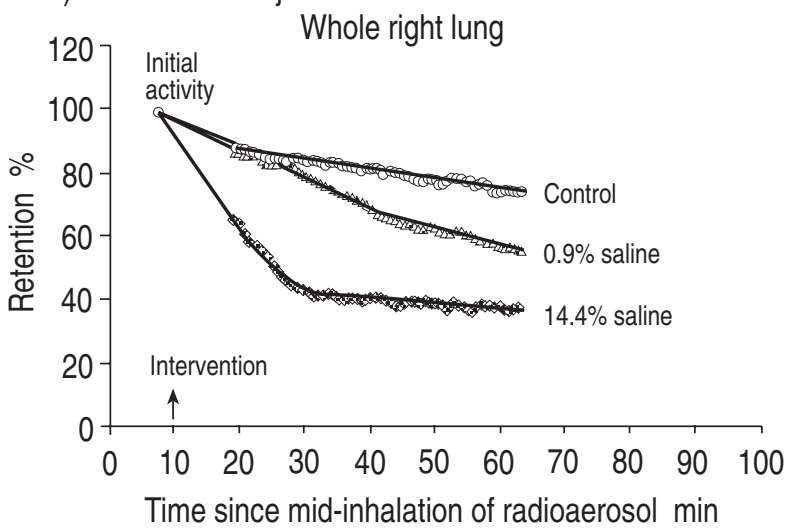

b) Healthy Subject 16

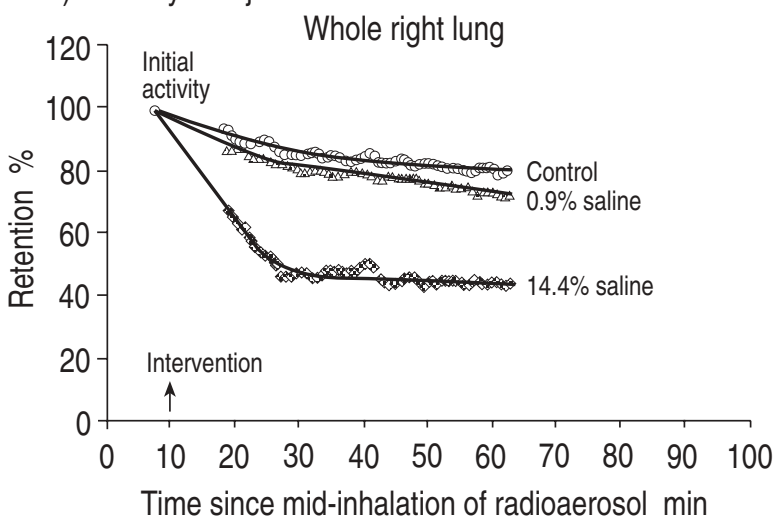

Fig. 1. - Example of the percentage retention curves of the whole right lung: a) in an asthmatic subjects and b) in a healthy subject, on the three study days as defined by the intervention: 1) control (no aerosol intervention); 2) $14.4 \%$ saline; and 3) $0.9 \%$ saline. The control study involved nasal breathing over the same time interval as the delivery of saline. This figure demonstrates the increase in the mucociliary clearance (initial activity - \% retained activity) in response to inhalation of $14.4 \%$ saline compared to $0.9 \%$ saline and control. It also demonstrates that the increase in the clearance rate started during the inhalation of the $14.4 \%$ saline and that the clearance reached its maximum in a relatively short time. $\bigcirc:$ control; $\Delta: 0.9 \%$ saline; $\diamond$ : $14.4 \%$ saline. 


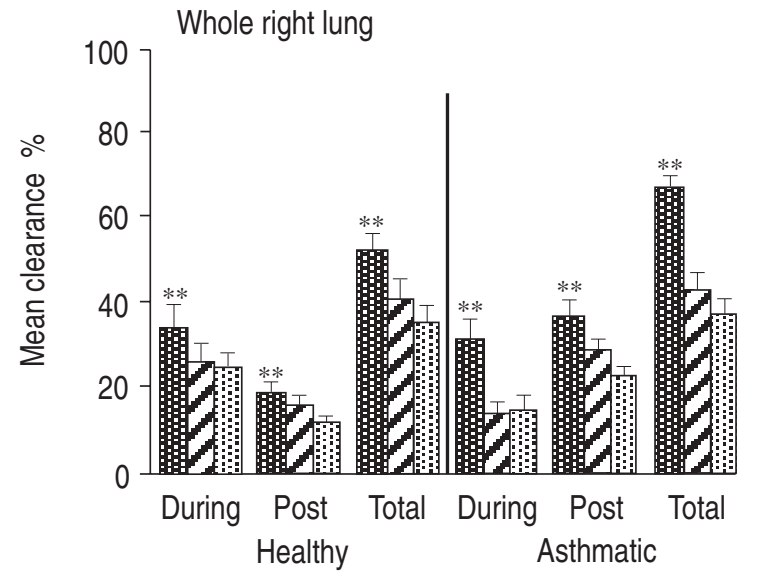

Fig. 2. - Percentage clearance of the whole right lung during, postintervention and total in $1 \mathrm{~h}$, on the three study days, in asthmatic $(n=12)$ and healthy $(n=10)$ subjects. Values are presented as mean \pm SEM. This figure demonstrates the significant increase in the mean clearance in response to inhalation of $14.4 \%$ saline, compared to $0.9 \%$ saline and control over the same time interval $(* * \mathrm{p}<0.001)$. The asthmatic subjects compared to the healthy, had a greater increase in clearance after $1 \mathrm{~h}$ in response to $14.4 \%$ saline $(\mathrm{p}<0.02)$. Both asthmatic and healthy subjects had similar clearance $(\mathrm{p}>0.6)$ after $1 \mathrm{~h}$ with $0.9 \%$ saline and control (less than 4\% difference). 䁕明 : 14.4\% saline; F : $0.9 \%$ saline; H:!:: control.

right lung (fig. 2) and its defined lung regions (fig. 3a-c) in the asthmatic subjects, suggesting that both large and small airways were affected by the hypertonic stimulus. By contrast, in the healthy subjects, while the MCC increased in the whole right lung (fig. 2), the central (fig. 3a) and the intermediate region (fig. 3b), it did not increase significantly in the peripheral region (fig. 3c). Furthermore, in the asthmatic subjects, the increase in mucociliary clearance in response to inhalation of $14.4 \%$ saline in the whole right lung, central region and intermediate region was of greater magnitude compared to the healthy subjects (figs. 2 and 3 ).

The increase in the MCC rate, that occurred in response to $14.4 \%$ saline, started during the inhalation of the saline. In fact, most of the increase in the clearance occurred during the inhalation of the $14.4 \%$ saline (more than $70 \%$ of the total mean increase in MCC measured in the whole right lung and central region). The exception to this was the intermediate region of the healthy subjects and the peripheral region of the asthmatic subjects, where only 35 and $3 \%$ of the total mean increase in the clearance, respectively, occurred during the inhalation of the $14.4 \%$ saline.

The MCC rate was increased up to 20 min post-inhalation of $14.4 \%$ saline aerosol, compared to control and $0.9 \%$ saline, in the whole right lung (fig. $4 \mathrm{a}$ and $\mathrm{b}$ ), central and intermediate region both of the asthmatic and healthy subjects. There was a marked increase in the clearance rate in the first $10 \mathrm{~min}$ after the inhalation of the $14.4 \%$ saline aerosol in the asthmatic subjects (fig. 4a). In the peripheral region of the asthmatic subjects, where there was no increase during inhalation, the increase in MCC rate was significant up to $30 \mathrm{~min}$. Thus, the overall duration of the increase in the MCC rate in response to $14.4 \%$ saline was similar in all regions in the asthmatic subjects.

Although the $0.9 \%$ saline, compared with the control, had a tendency to increase MCC after the inhalation of the
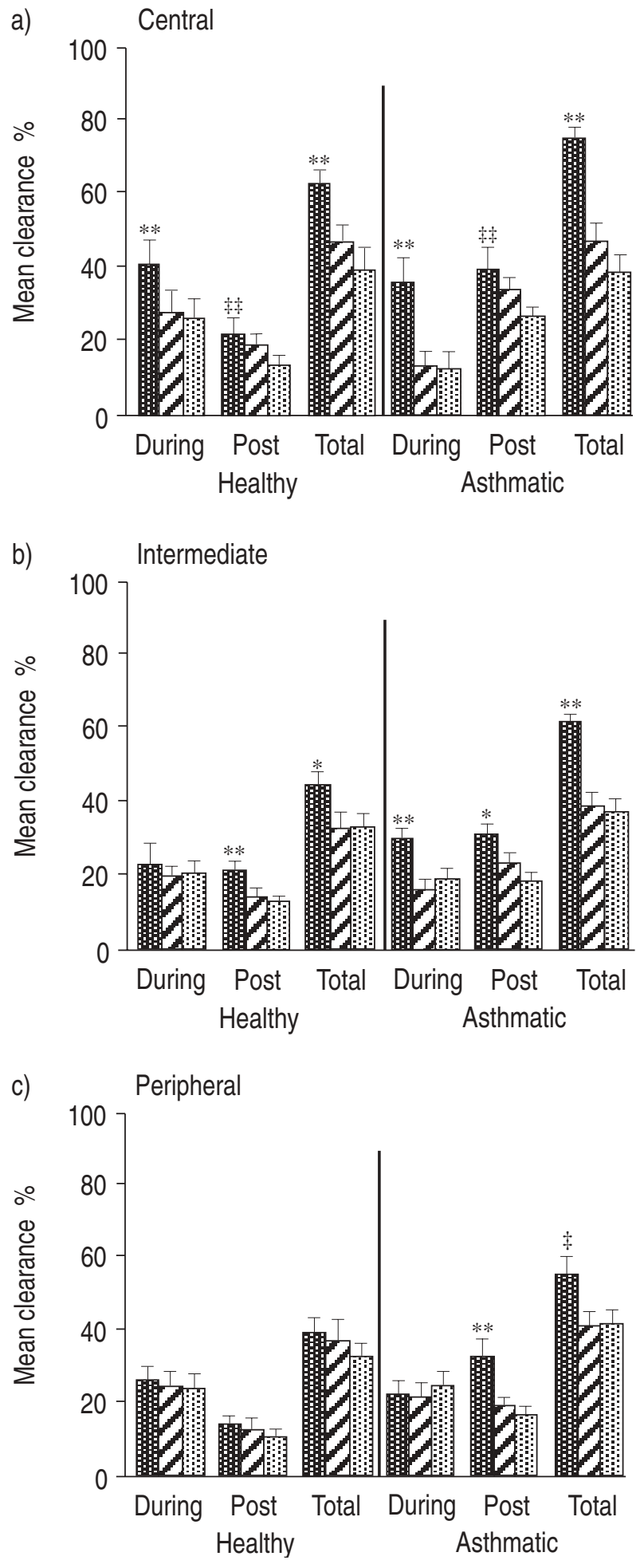

Fig. 3. - Percentage clearance of the: a) central; b) intermediate; and c) peripheral region of the right lung during, 45 min post-intervention and total in $1 \mathrm{~h}$, on the three study days, in asthmatic and healthy subjects. Values are presented a mean \pm SEM. this figure demonstrates the significant increase in the mean clearance in response to inhalation of $14.4 \%$ saline, compared to $0.9 \%$ saline and control over the same time interval $(\ddagger: \mathrm{p}<0.05 ; \uparrow+\mathrm{p}<0.01 ; *$ : $\mathrm{p}<0.005 ; * *: \mathrm{p}<0.001)$. The asthmatic subjects compared to the healthy, had a greater increase in clearance after $1 \mathrm{~h}$ in response to $14.4 \%$ saline (central $\mathrm{p}=0.07$; intermediate $\mathrm{p}<0.03)$. Both asthmatic and healthy subjects had similar clearance $(\mathrm{p}>0.2)$ in all regions, after $1 \mathrm{~h}$, with $0.9 \%$ saline and control. 明明: : $14.4 \%$ saline; $Z$ : 0.9\% saline; 

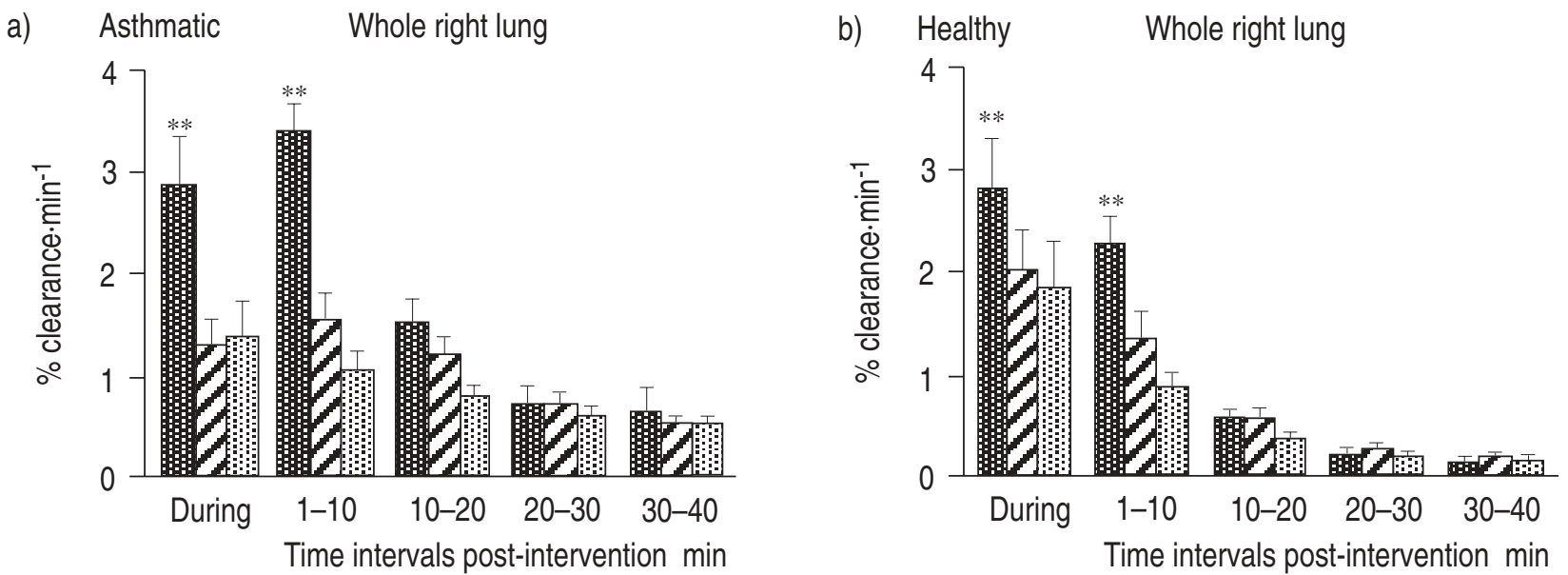

Fig. 4. - Percentage clearance-min-1 during and for each 10 min interval post-intervention in the whole right lung of the: a) asthmatic; and b) healthy subjects, on three study days. Values are presented as mean \pm sEM. This figure demonstrates the increased clearance rate during intervention and in the first 10 min post-intervention in response to inhaling $14.4 \%$, compared to $0.9 \%$ saline and control (**: p<0.001). The asthmatic subjects, compared to the healthy, had a marked increase in the clearance rate in the first 10 min post-inhalation of $14.4 \%$ saline ( $<<0.3$ ). 䀠明明 : 14.4\% saline; 7 : 0.9\% saline;

saline, the differences were only significant in the whole right lung $(\mathrm{p}<0.001)$ and only post-intervention, both in the asthmatic and healthy subjects. Asthmatic and healthy subjects had similar MCC after $1 \mathrm{~h}$ with both control (nasal resting breathing) and $0.9 \%$ saline in the whole right lung and in all regions ( $>>0.2)$ (less than $4 \%$ in the whole right lung and central region) as shown in figures 2 and 3 .

The results of the airway response to inhaling $14.4 \%$ saline, the nebulized saline volume and salt contained, and the delivery time are shown in table 1 for asthmatic and healthy subjects, respectively. Only a small volume of $14.4 \%$ saline needed to be nebulized, in a relatively short time, to provoke airway narrowing in asthmatic subjects (table 1). The mean nebulized dose to provoke a fall in FEV1 of 15\% (PD15) was $1.5 \mathrm{~mL}$.

The distribution of deposited $99 \mathrm{~m} \mathrm{Tc}$-sulphur colloid was not significantly different between the three study days, as shown in table 2. Asthmatic subjects appear to have a more central deposition than the healthy subjects, as indicated by the mean penetration indices $(\mathrm{p}<0.01)$.

Table 2. - Penetration indices and their percentage difference $(\% d)$ for the three study days for asthmatic and healthy subjects

\begin{tabular}{|c|c|c|c|c|c|c|}
\hline $\begin{array}{l}\text { Subj. } \\
\text { No. }\end{array}$ & $\begin{array}{l}14.4 \% \\
\text { saline }\end{array}$ & $\begin{array}{l}0.9 \% \\
\text { saline }\end{array}$ & Control & $\begin{array}{c}\% \mathrm{~d} \\
(14.4-0.9 \%)\end{array}$ & $\begin{array}{c}\% \mathrm{~d} \\
(14.4 \%-\mathrm{C})\end{array}$ & $\begin{array}{c}\% \mathrm{~d} \\
(0.9 \%-\mathrm{C})\end{array}$ \\
\hline \multicolumn{7}{|l|}{ Asthmatic } \\
\hline 1 & 0.262 & 0.240 & 0.224 & 9.2 & 17.0 & 7.1 \\
\hline 2 & 0.237 & 0.225 & 0.261 & 5.3 & -9.2 & -13.8 \\
\hline 3 & 0.336 & 0.360 & 0.318 & -6.7 & 5.7 & 13.2 \\
\hline 4 & 0.488 & 0.486 & 0.485 & 0.4 & 0.6 & 0.2 \\
\hline 5 & 0.207 & 0.335 & 0.301 & -38.2 & -31.2 & 11.3 \\
\hline 6 & 0.287 & 0.271 & 0.347 & 5.9 & -17.3 & -21.9 \\
\hline 7 & 0.417 & 0.438 & 0.470 & -4.8 & -11.3 & -6.8 \\
\hline 8 & 0.221 & 0.267 & 0.298 & -17.2 & -25.8 & -10.4 \\
\hline 9 & 0.267 & 0.295 & 0.297 & -9.5 & -10.1 & -0.7 \\
\hline 10 & 0.257 & 0.309 & 0.251 & -16.8 & 2.4 & 23.1 \\
\hline 11 & 0.239 & 0.269 & 0.301 & -11.2 & -20.6 & -10.6 \\
\hline 12 & 0.227 & 0.254 & 0.255 & -10.6 & -11.0 & -0.4 \\
\hline Mean & 0.287 & 0.312 & 0.317 & -7.8 & -9.2 & -0.8 \\
\hline $\mathrm{SD}$ & 0.086 & 0.080 & 0.082 & 12.9 & 13.8 & 12.9 \\
\hline p-value & & & & NS & NS & NS \\
\hline \multicolumn{7}{|l|}{ Healthy } \\
\hline 13 & 0.531 & 0.556 & 0.520 & -4.5 & 2.1 & 6.9 \\
\hline 14 & 0.389 & 0.359 & 0.368 & 8.4 & 5.7 & -2.4 \\
\hline 15 & 0.428 & 0.386 & 0.432 & 10.9 & -0.9 & -10.6 \\
\hline 16 & 0.403 & 0.479 & 0.500 & -15.9 & -19.4 & -4.2 \\
\hline 17 & 0.373 & 0.356 & 0.363 & 4.8 & 2.8 & -1.9 \\
\hline 18 & 0.375 & 0.460 & 0.383 & -18.5 & -2.1 & 20.1 \\
\hline 19 & 0.357 & 0.358 & 0.377 & -0.3 & -5.3 & -5.0 \\
\hline 20 & 0.492 & 0.471 & 0.550 & 4.5 & -10.5 & -14.4 \\
\hline 21 & 0.367 & 0.329 & 0.400 & 11.6 & -8.3 & -17.8 \\
\hline 22 & 0.235 & 0.252 & 0.272 & -6.7 & -13.6 & -7.4 \\
\hline Mean & 0.395 & 0.401 & 0.417 & -0.6 & -5.0 & -3.7 \\
\hline $\mathrm{SD}$ & 0.080 & 0.089 & 0.085 & 10.6 & 8.0 & 10.8 \\
\hline p-value & & & & NS & NS & NS \\
\hline
\end{tabular}

Subj: subject; NS: nonsignificant. 


\section{Discussion}

This study clearly demonstrates that inhalation of $14.4 \%$ saline aerosol increases MCC both in asthmatic and healthy subjects. However, there are differences in the magnitude and site of this response in the two groups. The increase in MCC was greater in the asthmatic compared to the healthy subjects. Inhalation of the hypertonic saline affected both the central and peripheral regions of the asthmatic subjects, whilst it affected mainly the central regions of the healthy subjects. In the central region, in both groups, most of the increase in $\mathrm{MCC}$ in response to $14.4 \%$ saline occurred during the inhalation of the hypertonic aerosol, whilst in the intermediate region in the healthy subjects and in the peripheral region in the asthmatic subjects it occurred after the inhalation. The duration of the increase in the MCC rate after the inhalation of the $14.4 \%$ saline was relatively short.

The present findings, in asthmatic and healthy subjects with normal baseline lung function and MCC, are consistent with the earlier findings of PAVIA et al. [2] and more recently of ROBINSON et al. [3], who both demonstrated that inhalation of $7 \%$ saline aerosol increases MCC in those with abnormal baseline.

The increase in MCC is most likely to be due to mediators released in response to hyperosmolarity of the airway surface liquid, because exposure of the human airways to a hyperosmolar stimulus causes release of histamine, prostaglandin $\mathrm{E}_{2}\left(\mathrm{PGE}_{2}\right)$ and leukotriene $\mathrm{C}_{4}$ from the mast cells [15-18], and possibly neuropeptides (e.g. substance P) from sensory nerves [18]. Animal studies, in vitro and in vivo, have shown that chemical mediators and neuropeptides can stimulate ciliary activity [19-21] by a mechanism which is not clearly understood but may involve neural stimulation of ciliary beat frequency via the cyclooxygenase pathway [21-23]. Histamine has been demonstrated to increase mucociliary clearance both in asthmatic and healthy subjects $[24,25]$. Additionally, hyperosmolarity of the airway fluid causes an increase in $\mathrm{Ca}^{2+}$ release from intracellular stores [26]. There is evidence that an increase in $\mathrm{Ca}^{2+}$ stimulates the ciliary beat frequency, possibly by regulating the use or availability of adenosine triphosphate (ATP) by the axoneme of the cilia [27].

The short duration of the increase in the MCC rate after the inhalation of $14.4 \%$ saline suggests that clearance of the radioaerosol may approach its maximum rapidly, considering that the mean clearance in $1 \mathrm{~h}$ from the whole right lung was 70 and $50 \%$ in asthmatic and healthy subjects, respectively, more than $70 \%$ of which occurred during the $3.5-7.5 \mathrm{~min}$ period of inhalation. Another possible explanation is that the cilia cannot beat as effectively after 10-20 min due to an increased depth of the periciliary fluid layer, because water has moved into the airway lumen in response to the osmotic stimulus. Mediators released in response to hyperosmolarity also have the potential to increase the volume of the airway surface liquid, either by stimulating chloride and mucus secretion or causing an increase in vascular permeability $[28,29]$. It is also possible that the stimulus for the increase in MCC has dissipated $20 \mathrm{~min}$ after the inhalation of $14.4 \%$ saline.

The differences between the MCC of asthmatic and healthy subjects in response to inhaling $14.4 \%$ saline could be accounted for by differences in the deposition of the radioaerosol or the deposition of the $14.4 \%$ saline. Asthmatic subjects appear to have a more central deposition of the radioaerosol than the healthy subjects. Also, the $14.4 \%$ saline aerosol was expected to have deposited more centrally in the asthmatic subjects because of the provoked bronchoconstriction, although experimental work showed no definite pattern in the deposition of hypertonic aerosol in asthmatic subjects [30]. However, the more central deposition in the asthmatic subjects does not explain the increased clearance from the deeper lung regions in response to the hypertonic stimulus. Furthermore, there may be differences in the mediators present in the airways between asthmatic and healthy subjects, depending on the extent of inflammation, and this may account for the differences in the magnitude of the response. It is also possible that the increase in MCC in the peripheral region in the asthmatics is due to mediators, originally released in the central airways, and distributed to the peripheral region via the bronchial circulation. This could explain why the increase in MCC in the peripheral region happened after the inhalation of the hypertonic saline, in contrast to the other regions where the increase in MCC started during the inhalation of the saline.

It is of interest that, for the $0.9 \%$ saline and control, both asthmatic and healthy subjects have similar total mean clearance (less than $4 \%$ differences in the whole right lung and central region). This makes it unlikely that radioaerosol deposition could account for the difference in the magnitude of the clearance, in response to inhaling $14.4 \%$ saline, between asthmatic and healthy subjects and suggests that the mediators released may be a factor in the difference.

The findings of this study qualitatively resemble the findings of the effect of ISH with dry air on mucociliary clearance, although the increase in MCC after the ISH with the dry air persisted for longer both in the asthmatic and healthy subjects compared with the present study. The difference in the duration of the increase in MCC is probably due to the different effect of the ISH and hypertonic saline on MCC during the intervention. Whilst hypertonic saline increases MCC immediately, the immediate effect of ISH is to decrease MCC probably by reducing the depth of the periciliary fluid layer. It is also possible that the strength of the stimulus determines the magnitude and the duration of the response. As only one concentration (14.4\%) of saline was used, a separate study with a range of concentrations would be needed to answer this point.

Instead of the usual $4.5 \%$ saline [4], to increase the osmolarity of the airway fluid and study its effect on MCC, we chose $14.4 \%$ saline to minimize the volume deposited, because large volumes of fluid could potentially uncouple the cilia from the mucus immediately. To induce a fall in FEV1 greater than $15 \%$ in mild asthmatic subjects, using $4.5 \%$ saline, up to $15-20 \mathrm{~mL}$ need to be delivered to the valve. If approximately $10 \%$ of this volume deposits in the airways, it could substantially increase the depth of the periciliary fluid layer, the total volume of which up to the 10th generation is estimated to be less than $1 \mathrm{~mL}$ [8]. We tried to overcome the problem of an excessive volume by using $14.4 \%$ saline. This concentration induced a fall in FEV1, greater than $15 \%$ in mild asthmatic subjects, with less than 2.5 $\mathrm{mL}$ being delivered to the valve.

Mucociliary clearance is one of the lung's defence mechanisms and the increase in mucociliary clearance above 
the normal baseline value in response to inhalation of hyperosmolar saline implies that it is a physiological response to clear accumulated secretions in the airways. The finding that mucociliary clearance increases in the healthy subjects after inhaling an aerosol of hypertonic saline may also have practical implications, as a response to a need to clear unwanted inhaled particles.

In summary, an increase in the osmolarity of the airway surface liquid increases mucociliary clearance both in asthmatic and healthy subjects. These findings are in keeping with our previous suggestion that the increase in mucociliary clearance after ISH with dry air is due to a transient hyperosmolarity of the periciliary fluid layer with the subsequent release of mediators that play a role in the stimulation of mucociliary clearance.

Acknowledgements: The authors would like to thank the technical staff of the Department of Nuclear Medicine for their help in carrying out this study and the subjects for volunteering for the study.

\section{References}

1. Daviskas E, Anderson SD, Gonda I, Chan HK, Cook P, Fulton R. Changes in mucociliary clearance during and after isocapnic hyperventilation in asthmatic and healthy subjects. Eur Respir J 1995; 8: 742-751.

2. Pavia D, Thomson ML, Clarke SW. Enhanced clearance of secretions from the human lung after the administration of hypertonic saline aerosol. Am Rev Respir Dis 1978; 117: 199-203.

3. Robinson M, Regnis JA, Bailey DL, King M, Bautovich GJ, Bye PTP. Effect of hypertonic saline, amiloride and cough on mucociliary clearance in patients with cystic fibrosis. A J Respir Crit Care Med 1996; 153.

4. Smith CM, Anderson SD. Inhalation provocation tests using nonisotonic aerosol. J Allergy Clin Immunol 1989; 84: 781-790.

5. Goldman AJ, Becklake MR. Respiratory function tests: normal values at medium altitudes and the prediction of normal results. Am Rev Respir Dis 1959; 79: 457-467.

6. Smith CM. The role of osmotic stimuli in the provocation of asthma. PhD Thesis 1988, University of Sydney, Sydney, Australia.

7. Gonda I. Pharmaceutical developments in therapeutic and diagnostic aerosols. Pharm Tech Japan 1986; 2: 883-893.

8. Anderson SD, Daviskas E, Smith CM. Exercise-induced asthma: a difference in opinion regarding the stimulus. Allergy Proc 1989; 10: 215-226.

9. Rodwell LT Anderson SD, Seale JP. Inhaled clemastine, an $\mathrm{H} 1$ antihistamine inhibits airway narrowing caused by aerosols of nonisotonic saline. Eur Respir J 1991; 4: 126-134.

10. Phipps PR, Gonda I. Droplets produced by medical nebulizers: some factors affecting their size and solute concentration. Chest 1990; 97: 1327-1332.

11. Phipps PR, Gonda I, Anderson SD. Apparatus for the control of breathing patterns during aerosol inhalation. J Aerosol Med 1992; 5: 155-170.

12. Bailey DL, Hutton BF, Walker PJ. Improved SPECT using simultaneous emission and transmission tomography. J Nucl Med 1987; 28: 844-851.
13. Bailey DL, Fulton RR, Jackson CB, Hutton BF. Dynamic geometric mean studies using a single headed rotating gamma camera. J Nucl Med 1989; 30: 1865-1869.

14. Phipps PR, Gonda I, Bailey DL, Borham P, Bautovich G, Anderson SD. Comparisons of planar and tomographic gamma scintigraphy to measure the penetration index of inhaled aerosols. Am Rev Respir Dis 1989; 139: $1516-1523$.

15. Gravelyn TR, Pan PM, Eschenbacher WL. Mediator release in an isolated segment in subjects with asthma. Am Rev Respir Dis 1988; 137: 641-646.

16. Maxwell DL, Hawksworth RJ, Lee TH. Inhaled nedocromil sodium reduces histamine release from isolated large airway segments of asthmatic subjects in vivo. Eur Respir $J$ 1993; 6: 1145-1150.

17. Silber G, Proud D, Warner J, et al. In vivo release of inflammatory mediators by hyperosmolar solutions. Am Rev Respir Dis 1988; 137: 606-612.

18. Jongejan RC, de Jongste JC, Raatgee RC, Stijnen T, Bonta IL, Kerrebijn KF. Effect of hyperosmolarity on human isolated central airway. Br J Pharmacol 1991; 102: 931-937.

19. Wanner A, Maurer D, Abraham WM, Szepfalusi Z, Sielczak M. Effects of chemical mediators of anaphylaxis on ciliary function. J Allergy Clin Immunol 1983; 72: 663-667.

20. Wanner A, Sielczak M, Mella JF, Abraham WM. Ciliary responsiveness in allergic and nonallergic airways. $J$ Appl Physiol 1986; 60: 1967-1971.

21. Wong LB, Miller IF, Yeates D. Pathways of substance $\mathrm{P}$ stimulation of canine tracheal ciliary beat frequency. J Appl Physiol 1991; 70(1): 267-273.

22. Wong LB, Miller IF, Yeates DB. Stimulation of tracheal ciliary beat frequency by capsaicin. J Appl Physiol 1990; 68(6): 2574-2580.

23. Wong LB, Miller IF, Yeates D. Regulatory pathways for the stimulation of canine tracheal ciliary beat frequency by bradykinin. J Physiol 1990; 422: 421-431.

24. Mussato DJ, Garrard CS, Lourenco RV. The effect of inhaled histamine on human tracheal mucus velocity and bronchial mucociliary clearance. Am Rev Respir Dis 1988; 138: 775-779.

25. Garrard CS, Mussato DJ, Lourenço RV. Lung mucociliary transport in asymptomatic asthma: effects of inhaled histamine. J Lab Clin Med 1989; 113: 190-195.

26. Eveloff JL, Warnock DG. Activation of ion transport systems during cell volume regulation. Am J Physiol (Renal Fluid Electrolyte Physiol 21) 1987; 252: F1-F10.

27. Lansley AB, Sanderson MJ, Dirksen EP. Control of the beat cycle of respiratory tract by $\mathrm{Ca}^{2+}$ and cAMP. $\mathrm{Am}$ J Physiol (Lung Cellular and Molecular Physiol) 1992; 263: L232-L242.

28. Umeno E, McDonaid DM, Nadel JA. Hypertonic saline increases vascular permeability in the rat trachea by producing neurogenic inflammation. J Clin Invest 1990; 85: 1905-1908.

29. Yager D, Shore S, Drazen JM. Airway luminal fluid: sources and role as an amplifier of bronchoconstriction. Am Rev Respir Dis 1991; 143: S52-S54.

30. Phipps PR, Gonda I, Anderson SD, Bailey D, Bautovich G. Regional deposition of saline aerosols of different tonicities in normal and asthmatic subjects. Eur Respir J 1994; 7: 1474-1482. 